\title{
Rifampicin Induced Nephrotic Syndrome: A Case Report
}

\author{
${ }^{1}$ Sumit Arora, ${ }^{2}$ Satish Mendonca, ${ }^{3}$ Arun Natarajan
}

\begin{abstract}
Introduction: Rifampicin is a potent antitubercular drug used in the treatment of tuberculosis (TB). It is known to cause nephrotoxicity of which nephrotic syndrome is a less common though well-known manifestation.
\end{abstract}

Case report: We present a case of rifampicin induced minimal change disease in a patient with HIV and TB who responded completely to the withdrawal of drug alone and did not require any specific therapy for nephrotic syndrome.

Keywords: Rifampicin, Nephrotic syndrome, Minimal change disease.

How to cite this article: Arora S, Mendonca S, Natarajan A. Rifampicin Induced Nephrotic Syndrome: A Case Report Journal of Medical Academics 2018;1(1):72-73.

\section{Source of support: Nil}

\section{Conflict of interest: None}

\section{INTRODUCTION}

Rifampicin is an essential antitubercular drug used as first-line treatment of tuberculosis. It is known to cause nephrotoxicity ${ }^{1-9}$ mostly in the form of acute interstitial nephritis or acute tubular necrosis and less commonly as rapidly progressive glomerulonephritis ${ }^{9,10}$ or nephrotic syndrome. ${ }^{2,5-8}$ Drug-induced minimal change disease responds well to drug withdrawal and steroid therapy ${ }^{1,11}$ We present a case of rifampicin induced MCD in an human immunodeficiency virus (HIV) patient who responded to drug withdrawal alone and recovered completely without any other therapeutic intervention. ${ }^{12}$

\section{CASE REPORT}

A 32-year-old army personnel presented with fever and significant weight loss of two months duration. On evalu-

\footnotetext{
${ }^{1}$ Assistant Professor, ${ }^{2}$ Consultant and Professor, ${ }^{3}$ Resident

${ }^{1}$ Medicine Base Hospital Delhi Cantt and Army College of Medical Science, New Delhi, India

${ }^{2}$ Nephrologist, Army Hospital Research and Referral, New Delhi Cantonment, India

${ }^{3}$ Base Hospital Delhi Cantonment, India

Corresponding Author: Sumit Arora, Consultant Physician, Assistant Professor, Medicine Base Hospital Delhi Cantonment and Army College of Medical Science, New Delhi, India, e-mail: drsumit76@gmail.com
}

ation found to have extra pulmonary tuberculosis and HIV infection. His CD4 count was 244 cells/microlitre. His baseline blood counts, renal function, and urine analysis were within normal limits. He was started on antitubercular therapy with rifampicin $600 \mathrm{mg}$, isoniazid $300 \mathrm{mg}$, ethambutol $1000 \mathrm{mg}$, and Pyrazinamide $1500 \mathrm{mg}$ and two weeks later started on anti-retroviral therapy (ART) with Tenofovir, Lamivudine, and Efavirenz. He was tolerating therapy well and was asked for the review after four weeks. On review, he complained of fatigue and swelling of feet. On evaluation, clinically he was normotensive and had mild pitting ankle edema. Urine analysis revealed $4+$ proteins with no significant casts, red blood cells (RBCs) or white blood cells (WBCs). Twenty four hour urinary protein evaluation showed 4-gram proteinuria per day. His blood cell counts including eosinophil counts and renal function tests including urea, creatinine, uric acid and electrolytes were normal. Serum Albumin was $2.2 \mathrm{gram} / \mathrm{dL}$, lipid profile and blood sugar were within normal limits. HBsAg was negative. Anti hepatitis $\mathrm{C}$ virus (HCV) antibodies were positive though HCV Ribonucleic acid (RNA) was undetectable and repeat HCV antibodies turned negative after six months. His HIV RNA was 100 copies per ml. A kidney biopsy revealed a nonproliferative glomerulopathy with no significant glomerular immune deposits, no evidence of segmental sclerosis or any crescent formation and insignificant interstitial fibrosis and tubular atrophy.

Rifampicin-induced Minimal change disease was suspected, and he was switched from Rifampicin to Rifabutin and started on angiotensin-converting enzyme -I (ACE-I). He was followed up with no other intervention. Proteinuria regressed to $760 \mathrm{mg}$ per day after one month and was $206 \mathrm{mg}$ per day at six months of rifampicin withdrawal. Serum albumin levels returned to normal within 6 weeks. His ammonia tolerance test (ATT) was stopped after 6 months and there is no recurrence of significant proteinuria on follow up at twelve months.

\section{DISCUSSION}

Rifampicin is an antitubercular drug used as an essential component of first-line antitubercular therapy. It is associated with several forms of nephrotoxicity. ${ }^{2-10}$ The most common form of rifampicin induced renal injury is acute allergic interstitial nephritis and acute tubular necrosis. The latter is often though not always associated with 
autoimmune hemolytic anemia with hemoglobinuria and thrombocytopenia. Less commonly it presents with rapidly progressive renal failure, ${ }^{9,10}$ light chain proteinuria $^{4}$ or frank nephrotic syndrome. .-7,13 $^{5}$

Our patient presented with nephrotic range proteinuria and hypoalbuminemia approximately 7 weeks after starting antitubercular therapy and 5 weeks after AR. Although tenofovir is well known to cause tubular toxicity, it does not present with nephrotic syndrome. We ruled out all other common secondary causes of nephrotic syndrome in our patient. There was no other significant past medical history or history of any other drug intake. We suspected Rifampicin induced nephrotic syndrome which was confirmed by rapid regression of proteinuria with drug withdrawal.

Although there are no definite mechanisms offered for Rifampicin induced MCD, a hypersensitivity mechanism has been suggested in many drug-induced MCD cases wherein the drug exposure induces activation of inflammatory or immune cells causing glomerular injury and $\mathrm{MCD} .^{12}$ Another possible mechanism of MCD is via direct toxin effect on glomerular epithelial cells resulting in abnormal permeability and effacement of foot processes. ${ }^{12}$ Neugarten et al. ${ }^{6}$ reported a case of a rifampicin induced nephrotic syndrome and described the patient as having acute interstitial nephritis with heavy proteinuria and effacement of glomerular epithelial cells. They suggested that cell-mediated and humoral immune response to rifampicin therapy could lead to the development of glomerular injury and nephrotic syndrome. In our case, there was no significant glomerular immune deposits or immune complex-mediated glomerular injury. Hence direct toxin effects due to drug exposure are the is the likely mechanism of MCD in this case.

In many cases withdrawal of the offending drug can lead to complete remission of proteinuria and glucocorticoids may hasten recovery and remission of proteinuria. ${ }^{12}$ We came across few cases of rifampicin induced MCD treated with drug withdrawal and a short course of glucocorticoids with complete recovery. ${ }^{7}$ However as in our patient there is only one other case report of rifampicin induced MCD where the patient recovered completely with drug withdrawal alone. ${ }^{13}$

Hence we suggest a wait and watch approach in a case of rifampicin induced minimal change disease with drug withdrawal alone and steroid therapy may only be considered in those cases where drug withdrawal alone does not ameliorate proteinuria adequately. Also, rifabutin was well tolerated as a substitute to rifampicin in our patient as an alternative to rifampicin and did not lead to recurrence of proteinuria.

\section{REFERENCES}

1. Waldman M, Crew RJ, Valeri A, Busch J, Stokes B, Markowitz $\mathrm{G}$, et al. Adult minimal-change disease: clinical characteristics, treatment, and outcomes. Clin J Am Soc Nephrol. 2007;2:445-453.

2. Covic A, Goldsmith DJ, Segall L, Stoicescu C, Lungu S, Volovat C, et al. Rifampicin-induced acute renal failure: a series of 60 patients. Nephrol Dial Transplant. 1998;13:924-929.

3. Muthukumar T, Jayakumar M, Fernando EM, Muthusethupathi MA. Acute renal failure due to rifampicin: a study of 25 patients. Am J Kidney Dis. 2002;40:690-696.

4. De Vriese AS, Robbrecht DL, Vanholder RC, Vogelaers DP, Lameire NH. Rifampicin-associated acute renal failure: pathophysiologic, immunologic, and clinical features. Am J Kidney Dis. 1998;31:108-115.

5. Kohno K, Mizuta Y, Yoshida T, Watanabe H, Nishida $H$, Fukami K, et al. Minimal change nephrotic syndrome associated with rifampicin treatment. Nephrol Dial Transplant. 2000;15:1056-1059.

6. Neugarten J, Gallo GR, Baldwin DS. Rifampin-induced nephrotic syndrome and acute interstitial nephritis. Am J Nephrol. 1983;3:38-42.

7. Tada T, Ohara A, Nagai Y, Otani M, Ger YC, Kawamura S. A case report of nephrotic syndrome associated with rifampicin therapy. Nihon Jinzo Gakkai Shi. 1995;37:145-150.

8. Rekha VV, Santha T, Jawahar MS. Rifampicin-induced renal toxicity during retreatment of patients with pulmonary tuberculosis. J Assoc Physicians India. 2005;53:811-813.

9. Murray AN, Cassidy MJ, Templecamp C. Rapidly progressive glomerulonephritis associated with rifampicin therapy for pulmonary tuberculosis. Nephron. 1987;46:373-376.

10. Yoshioka K, Satake N, Kasamatsu Y, Nakamura Y, Shikata N. Rapidly progressive glomerulonephritis due to rifampicin therapy. Nephron. 2002;90:116-118.

11. Black DA, Rose G, Brewer DB. Controlled trial of prednisone in adult patients with the nephrotic syndrome. Br Med J. 1970;3:421-426.

12. Glassock RJ. Secondary minimal change disease. Nephrol Dial Transplant. 2003;18(Supply 6):vi52-vi58.

13. Dong HP, Sul AL, Hyeon JJ, Tae HY, Shin-Wook K et al. Rifampicin induced minimal change disease is improved after cessation of rifampicin without steroid therapy. Yonsei Med J. 2015;56(2):582-585. 